\title{
Influence of fiber content on the mechanical and thermal properties of kenaf fiber reinforced thermoplastic polyurethane composites.
}

\begin{abstract}
The aim of this paper is to study the influence of fiber content on mechanical (i.e. tensile, flexural, impact, hardness and abrasion resistance) and thermal (i.e. TGA) properties of Kenaf bast fiber reinforced thermoplastic polyurethane (TPU) composites. The composite was prepared by melt-mixing method, followed by compression molding process. Different fiber loadings were prepared; namely, 20\%, 30\%, 40\%, and 50\% weight percent. A $30 \%$ fiber loading exhibited the best tensile strength, while modulus increased with increase of fiber content, and strain deteriorated with increase of fiber content. Flexural strength and modulus increased with increase of fiber loading. Increase of fiber loading resulted in decline in impact strength. Hardness increased by addition of 30\% fiber content. Abrasion resistant decreased with increase of fiber loading. Fiber loading decreased thermal stability of the composite.
\end{abstract}

Keyword: composites 